\title{
Análise matemática da evolução da cirurgia da base do crânio
}

\author{
Marcos Augusto Stávale Joaquim* \\ Instituto de Neurociências, São Paulo, SP
}

RESUMO

Utilizando-se da geometria e da trigonometria, o autor estuda especialmente o campo cirúrgico e propõe uma metodologia para se avaliar, matematicamente, as ampliações das craniotomias utilizadas nos acessos à base do crânio.

PALAVRAS-CHAVE

Cirurgia da base do crânio. Craniotomia. Craniometria.

\section{ABSTRACT}

A mathematical methodology to evaluate ampliations obtained through craniotomy variations Using geometry and trigonometry, the author studies the spacial conformation of the surgical fields and introduce a mathematical methodology to study the ampliations of the craniotomies used to approach the skull base.

\section{KEYWORDS}

Skull base surgery. Craniotomy. Craniometry.

\section{Introdução}

A evolução da cirurgia oncológica da base do crânio pode ser traduzida pela ampliação do número de técnicas de abordagem cirúrgica disponíveis e de suas variações. Esses conhecimentos permitiram uma melhor manipulação cirúrgica do plano anatômico entre o viscerocrânio e neurocrânio, compartimentos estes que são separados por uma superfície óssea irregular, anfractuosa e atravessada por diversas estruturas vasculares e nervosas.

O planejamento microcirúrgico relacionado a essa superfície laminar óssea irregular implica não apenas o isolamento e a preservação daquelas estruturas vasculares e nervosas, como também a perspectiva de se abordar cirurgicamente o neurocrânio por meio do viscerocrânio, minimizando-se a retração cerebral. A remoção dessa superfície óssea permite o deslocamento do conteúdo do viscerocrânio e dos feixes vasculares e nervosos, ascendentes e descendentes, que a atravessam. Postula-se também que essa remoção óssea permite a ampliação do campo operatório - para a manipulação do instrumental e para a mobilização angular do eixo do campo visual do microscópio cirúrgico - e a diminuição da distância entre a superfície da área operatória e o alvo cirúrgico, profundamente situado.
Essa evolução da cirurgia oncológica determinou uma ampliação dos conceitos de operabilidade e ressecabilidade das neoplasias da base do crânio, assim como das possibilidades de preservação funcional das estruturas manipuladas, talvez interferindo nos conceitos de cura e paliação dessas neoplasias ${ }^{5}$. Certos estudos ${ }^{1,7,9,11,20,26,33}$ sugerem os benefícios do radicalismo das ressecções em meningeomas, visto que os resultados da radioterapia não são definitivos, exceto pelos melhores resultados da radiocirurgia ${ }^{12}$.

Embora as publicações experimentais e sobre doentes operados se multipliquem, principalmente no que se refere às vias de acesso anterolaterais e posterolaterais à base do crânio, não há estudos que quantifiquem efetivamente, em valores absolutos ou relativos, as vantagens das diferentes técnicas utilizadas.

O objetivo deste estudo é o de planejar a quantificação das vantagens dessa técnica sob dois aspectos: a ampliação angular do campo operatório em direção ao viscerocrânio, associada à maior exposição e à menor retração cirúrgicas do encéfalo; e a diminuição da distância entre o alvo do cirurgião e a superfície do campo operatório. Podemos estudar morfologicamente cada setor da extensão basal das craniotomias e

*Neurocirurgião. Doutor em Medicina pela FMUSP. 
averiguar suas vantagens numericamente, mediante análises compartimentalizadas que têm como base comparativa as craniotomias classicamente utilizadas a partir da qual são medidos os benefícios das extensões basais das osteotomias.

Assim, nossa hipótese é a de que as extensões cirúrgicas basais no crânio têm uma utilidade prática, matematicamente demonstrável, para otimizar o tratamento cirúrgico dos tumores da base do crânio. Essa demonstração matemática baseia-se primeiramente na avaliação dos encurtamentos das distâncias entre a superfície do campo operatório e o objetivo cirúrgico obtidos com essa técnica, comparadas com as correspondentes respectivas obtidas com as craniotomias convencionais. Em segundo lugar, realiza-se o cálculo dos ângulos de expansão basal do campo cirúrgico em diversos planos obtida pela remoção óssea adicional, em relação às craniotomias convencionais. Tais expansões angulares não são comparáveis com a craniotomia convencional, visto que se admite que seu valor absoluto na cranionomia clássica corresponda a zero; entretanto, osteotomias basais adicionais podem ter seus ângulos de ganho de exposição comparados entre si nas diversas técnicas operatórias (Figura 1). Para simular objetivos cirúrgicos profundos, são escolhidos pontos ósseos de referência anatômica, próximos ao centro do crânio, e para simular a superfície do campo cirúrgico são escolhidos pontos de reparo ósseo superficiais que correspondem aos limites das craniotomias que podem ser realizadas, ou seja, da craniotomia convencional e da que se pretende estudar. Todo o estudo pode ser realizado considerando-se exclusivamente a topografia óssea do crânio, pois o conhecimento da anatomia correlata permite inferir as possibilidades de manipulação do tecido adjacente aos pontos de referência ou pontos de reparo anatômico.

Por exemplo, o acesso osteoplástico pela remoção de retalho ósseo em bloco único envolvendo as extensões orbitária, zigomática e esfenoidal máximas da craniotomia frontotemporal convencional, que pode ser complementado por osteotomias adicionais, constitui a mais ampla técnica de exposição cirúrgica da região anterolateral da base do crânio. Esse acesso ampliado e executado em retalho ósseo único é uma combinação das vias de acesso cirúrgico previamente utilizadas, fundidas em uma só craniotomia e complementada por osteotomias diversas ${ }^{14}$. Sua utilização inclui-se como parte do tratamento cirúrgico oncológico das doenças orbitárias, esfenoidais, frontais e temporais, que têm, freqüentemente, diferentes extensões para o neurocrânio e para o viscerocrânio.

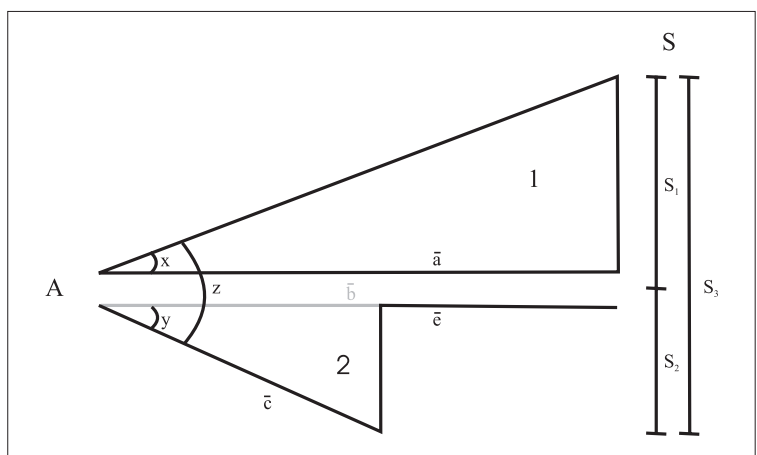

Figura 1 - Representação esquemática dos ângulos de exposição cirúrgica contidos no plano de secção longitudinal do campo cônico. $O$ triângulo 1 representa o campo operatório normal da craniotomia fronto-temporal, cujo ângulo de exposição (x) é obtido à custa da retração do cérebro, que é distanciado da base do crânio.

O triângulo 2 representa o campo operatório obtido pela ampliação basal da craniotomia, observando-se seu menor comprimento e o ângulo adicional de exposição (y) obtido pela ampliação da craniotomia e que pode ser somado ao ângulo expositivo obtido pela retração $x$, constituindo o ângulo $z$, ou deste subtraído, se se deseja trabalhar através do viscerocrânio e minimizar a retração cerebral. $O$ alvo cirúrgico A distancia-se o comprimento à da superfície do campo operatório (S). Esta linha a a está contida na base do crânio. Após removermos, hipoteticamente, o osso da base do crânio no comprimento è teremos a nova distância, menor, b. Entretanto, como houve ampliação do ângulo de exposição cirúrgica (y), a nova distância real pela base do crânio será $\bar{c}$, que é um eixo contido no plano formado pelo assoalho de viscerocrânio. A altura $S_{1}$ é o diâmetro superficial do campo convencional e a altura $S_{2}$ é o diâmetro superficial do campo adicional obtido pela extensão basal da craniotomia. A altura $S_{3}$ corresponderia à somação das alturas previamente citadas.

\section{Conceitos de "base do crânio" e de "cirurgia da base do crânio"}

Considera-se, rotineiramente, como "base do crânio”, sob o ponto de vista neurocirúrgico, todo o conjunto ósseo situado abaixo da linha circunferencial que passa pela protuberância occipital externa e pela glabela. Complementa-se o dimensionamento de um compartimento definindo, para esse trabalho, com um limite inferior constituído de dois outros planos paralelos ao da linha circunferencial citada acima: um que passa pelo ápice dos processos pterigóideos, e outro que passa pela base dos condilos occipitais, paralelos à fossa craniana média. Este compartimento inclui porções do neurocrânio e do víscero ou esplancnocrânio, com seu conteúdo vascular, nervoso, meníngeo e visceral, cujos componentes podem atravessar a lâmina óssea de transição entre os setores intra e extracranianos, lâmina esta que apresenta superfície visceral ou inferior e uma superfície neural ou superior. 
Consideramos como “cirurgia da base do crânio” a cirurgia realizada na região entre os planos citados acima, que é constituída de um conjunto de técnicas cuja velocidade de evolução acelerou-se nos últimos anos. Os objetivos da cirurgia da base do crânio dividem-se em três procedimentos: o procedimento de exposição, o de exérese e o de reconstrução. Portanto, a evolução técnica consiste em melhorar a exposição cirúrgica para permitir uma exérese mais completa e menos iatrogênica das neoplasias, e que seja passível de correção estética ou funcional satisfatória no momento da reconstrução das incisões e excisões praticadas pelo cirurgião. A filosofia da cirurgia da base do crânio implica aumentar, equilibradamente, os conceitos de operabilidade, ressecabilidade e preservação funcional. Para tanto, é necessário o conhecimento exato do que cada via de acesso cirúrgico pode fornecer para otimizar o procedimento.

Observa-se que os tumores benignos da base do crânio, freqüentemente, não são passíveis de remoção radical em virtude do comprometimento de estruturas de difícil acesso, ou cuja manipulação é arriscada. Observa-se também que os tumores malignos da base do crânio, embora não passíveis de ressecção completa, têm a radicalização de sua ressecção também dificultada, de maneira que o excesso de agressividade cirúrgica pode comprometer a qualidade da vida dos doentes, bem como de sua longevidade. Esta é a motivação para o aperfeiçoamento dessas cirurgias, que podem trazer benefícios ao doente.

\section{Conceitos de "campos cilíndricos" e "campos cônicos"}

A definição de "campos cilíndricos” parte da suposição de que o procedimento microcirúrgico pode ser realizado por um campo tubular cujas extremidades estão em contato, respectivamente, com o alvo da cirurgia e com a superfície do campo operatório. Tal campo é utilizado, na prática, quase que somente quando se trabalha com afastadores especulares que atingem o tumor. Entretanto, deve-se considerar matematicamente a estrutura desse campo cirúrgico e as modificações a que ele pode ser submetido quando é encurtado (diminuição do seu eixo) ou alargado (ampliação do seu diâmetro).

O campo cilíndrico ou tubular pode relacionar-se a um alvo hipotético, central em relação ao seu eixo e ao seu plano de secção profunda; ou a um alvo lateral, fora do eixo central, mas contido no mesmo plano, ou a um alvo superficial. Obviamente, outras posições hipotéticas de alvos podem ser consideradas. Entretanto, essas três são suficientes para a compreensão dos parâmetros relacionados a esses campos (Figura 2).

Em relação ao alvo central, o ângulo de exposição para a manipulação cirúrgica passa pela borda do plano da superfície externa ou superficial do cilindro. Se mais lateral o alvo, preserva-se a angulação do campo de exposição, mas quanto mais superficial for tal alvo, maior será a ampliação deste ângulo de exposição. Tal fenômeno está representado na figura 2.

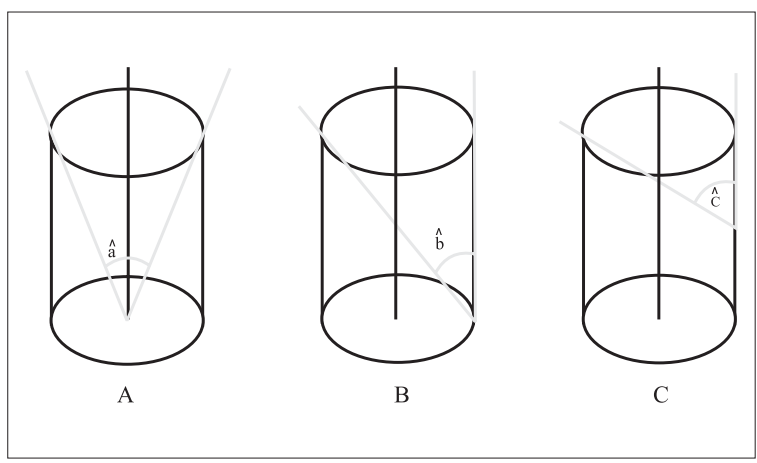

Figura 2 - Representação esquemática de campos cilíndricos com alvo central (A), lateral (B) e superficial (C). Nota-se o eixo do cilindro e os ângulos de exposição $\hat{a}, \hat{b} e \hat{c}$. Nestes casos $\hat{a}=\hat{b}<\hat{c}$.

Consideram-se, a seguir, as repercussões do encurtamento do eixo do cilindro e da ampliação de seu diâmetro. No encurtamento do eixo do cilindro, que corresponde ao encurtamento do campo operatório pela maior remoção óssea, percebe-se que, em relação aos alvos central, lateral e superficial, amplia-se o ângulo de exposição, além de aproximar-se o alvo do plano de secção superficial. Tal fenômeno é representado na figura 3.

Em relação ao aumento do diâmetro do cilindro, que representa o alargamento do campo operatório obtida pelas osteotomias, observa-se que, para qualquer alvo, existe um aumento do ângulo de exposição cirúrgica, conforme demonstra a figura 4. Portanto, a combinação dos procedimentos citados otimiza o aumento dos ângulos de exposição cirúrgica e aproxima o cirurgião do seu alvo, considerando-se a hipótese da existência de campos cilíndricos regulares.

A definição do “campo cônico” parte da hipótese ou suposição de que a morfologia do campo microneurocirúrgico apresenta as dimensões de um cone. Tal conformação é freqüentemente representada em 


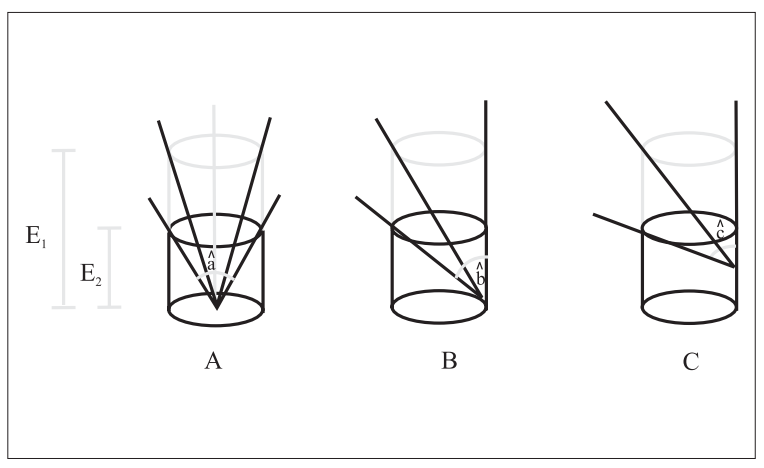

Figura 3 - Representação esquemática da redução do comprimento do eixo do campo cilíndrico. Em

pontilhado são delineados os campos superficiais e em

linhas cheias são delineados os campos encurtados no comprimento $\mathrm{E} 1$ para o comprimento $\mathrm{E2}$.

Há aumento dos ângulos de exposição obtidos para alvos centrais $(\hat{a})$, laterais

$(\hat{b})$ e superficiais $(\hat{c})$.

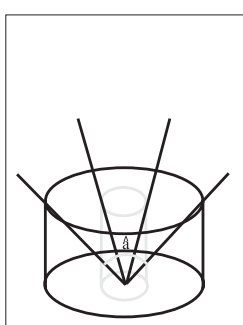

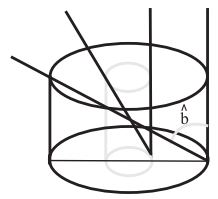

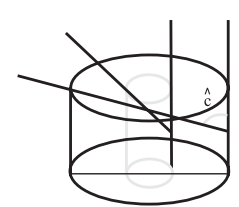

C
Figura 4 - Representação esquemática das repercussões do aumento do diâmetro do campo cilíndrico sobre o ângulo de exposição de alvos centrais, laterais e superficiais. Há ampliação dos ângulos iniciais para novos ângulos de

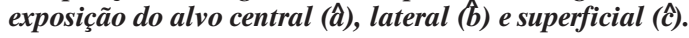

ilustrações pertencentes a publicações prévias, provavelmente de maneira inconsciente pelos autores.

Se considerarmos a forma cônica do campo operatório, sua base corresponderá à superfície do mesmo, e seu ápice, ao alvo cirúrgico. A área da secção transversa da sua base será a área da superfície do campo operatório. O encurtamento da distância longitudinal, ou a limitação da altura do cone, corresponderá à aproximação da superfície do campo cirúrgico e, portanto, do cirurgião ao seu alvo. Tal redução não fornece ampliação angular do campo, se considerarmos um alvo apical, mas sim se considerarmos um alvo superficial, conforme a representação esquematizada na figura 5 .

A ampliação diametral proporcional da base ou da área de secção transversa do cone, pelas osteotomias,

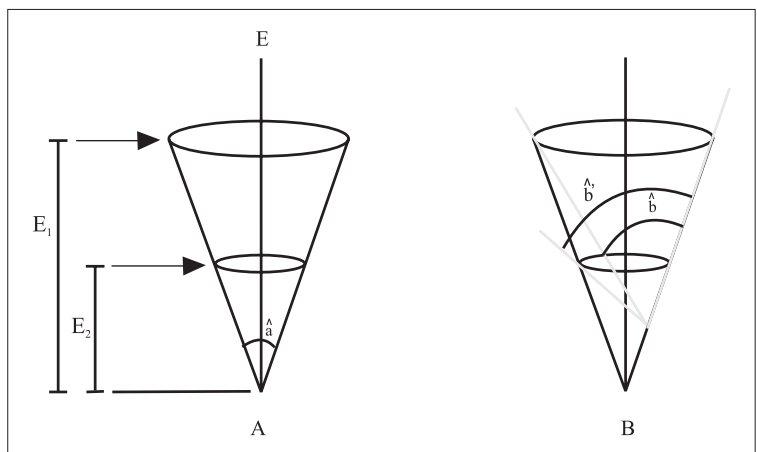

Figura 5 - Representação esquemática das repercussões do encurtamento do comprimento do campo cônico de $E_{1}$ para

$E_{2}$. No cone A, com alvo apical, o ângulo de exposiçãao permanece o mesmo (a). No cone $B$, com alvo superficial, o ângulo de exposição $\hat{b}$ amplia-se para $\hat{b}$ '

por outro lado, fornecerá uma ampliação do ângulo de exposição cirúrgica para alvos apicais e superficiais, conforme demonstra a figura 6.

Portanto, sobre os campos cônicos, a otimização da exposição cirúrgica dar-se-á pela diminuição da altura do cone e do aumento dos seus diâmetros. Assim, a combinação desses fenômenos matemáticos fornece maior espaço para o trabalho do cirurgião.

Os campos neurocirúrgicos são considerados, em geral, cônicos, pois na prática observa-se que essa é a principal conformação tridimensional destes. Neste estudo, para avaliar os benefícios em relação a ângulos de exposição cirúrgica, consideram-se os ângulos contidos no plano da secção longitudinal do cone que passa pelo seu maior diâmetro, e que o divide em dois meios cones (Figura 7).

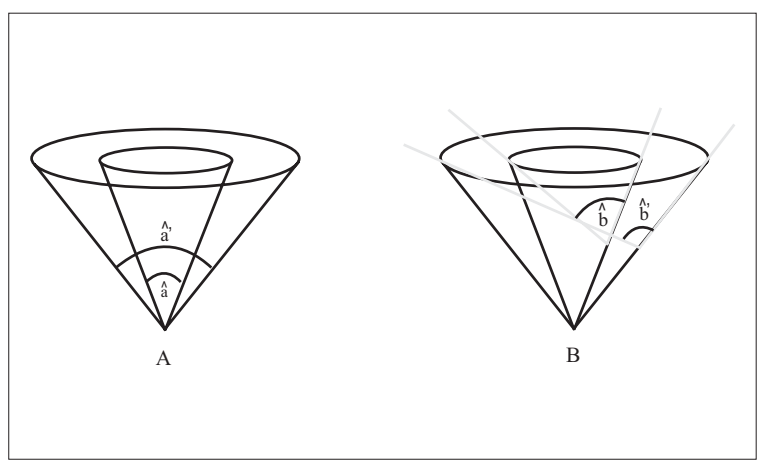

Figura 6 - Representação esquemática das repercussões da ampliação diametral do campo cônico. No cone A, com alvo apical, nota-se a ampliação do ângulo de exposição para $\hat{a}$.

No cone B, com alvo superficial, nota-se ampliação do ângulo inicial de exposição para $\hat{b}$. 


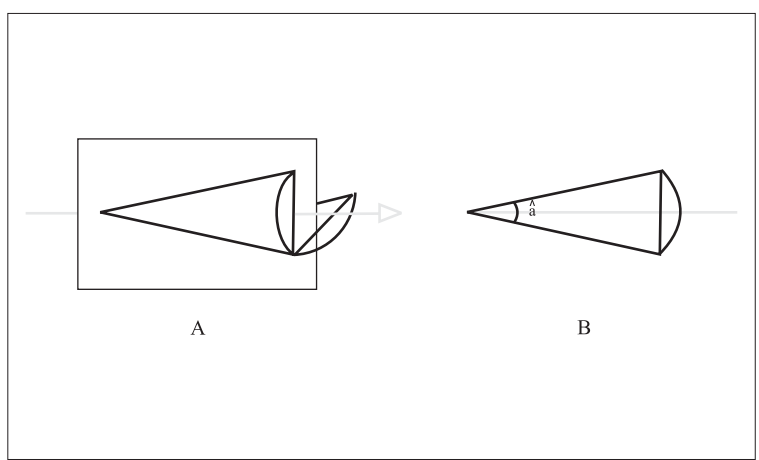

Figura 7 - Representação esquemática do plano de secção longitudinal do cone $(A)$, que fornece uma superfície plana no cone $(B)$, que conterá os ângulos a serem estudados $(\hat{a})$.

Dentro do plano que dividiu o campo cônico, podemos considerar os ângulos de ampliação cirúrgica. Como exemplo de esquema matemático, demonstramos na figura 1 como podem ser realizados os cálculos planares da ampliação dos ângulos de exposição cirúrgica basais em relação às craniotomias convencionais, que são as craniotomias de referência. Nota-se, entretanto, que os ângulos a serem determinados serão os ângulos que se obtêm para exposição adicional (ou para minimizar a retração cerebral), mediante remoção óssea da base do crânio, e não os ângulos somados à custa dos ângulos obtidos pela retração cerebral e dos ângulos de exposição basal adicionais. Tratar-se-á, portanto, de uma comparação com o valor absoluto inicial de zero, o que simboliza e significa a ausência da expansão basal da craniotomia frontotemporal convencional. Diferentemente, em relação ao cálculo do encurtamento das distâncias de acesso cirúrgico, tratar-se-á, este, da comparação entre as distâncias obtidas na realização da craniotomia clássica, e portanto diferentes de zero, com os valores obtidos com a craniotomia em estudo (Figura 1).

Para efeito de pesquisa, consideramos os campos como cônicos, arbitrariamente. Entretanto, na prática cirúrgica, o que provavelmente ocorre é a existência de campos "mistos" e "combinados". Definimos como campos "mistos" aqueles intermediários, sob o ponto de vista morfológico, entre os campos cilíndricos e os cônicos, e que são representados por um cone truncado por um plano transverso paralelo ou não ao plano basal, conforme exemplifica a figura 8. Definimos como campos "combinados" aqueles ramificados, que correspondem, na prática, à permanente e dinâmica alteração morfológica do campo conforme o cirurgião manipula esta ou aquela estrutura, variando a cada momento o seu objetivo espacial nas fases de dissecção e exérese (Figura 9).

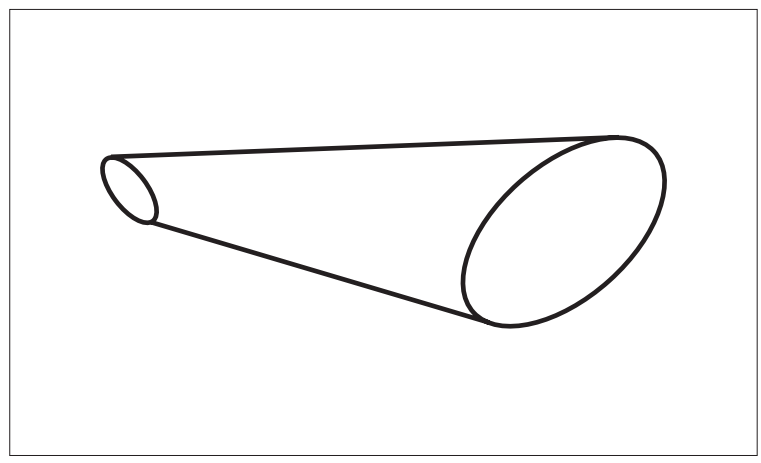

Figura 8 - Representação esquemática do campo misto.

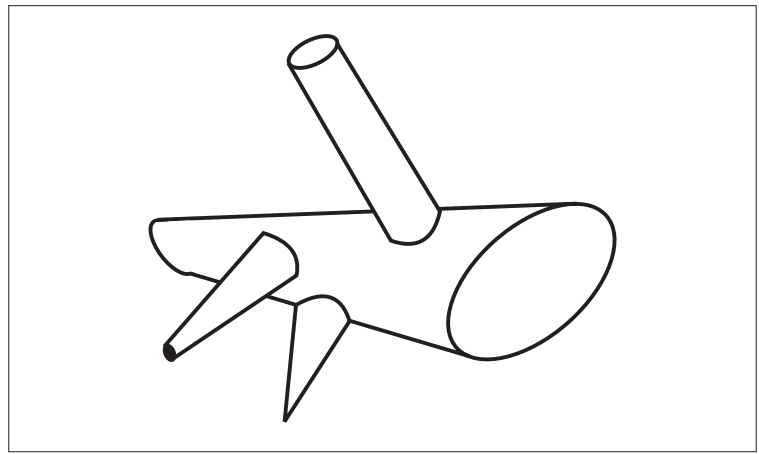

Figura 9 - Representação esquemática do campo combinado.

Esses raciocínios formam a base dos procedimentos que permitem a determinação numérica do encurtamento das distâncias de acesso medidas ao longo do plano da base do crânio, que é o plano da base do campo cirúrgico, e a determinação numérica dos ângulos obtidos por meio da extensão basal da craniotomia.

\section{Retração cerebral}

A abordagem de estruturas profundamente situadas na base do crânio implica deslocar-se o tecido cerebral, através de instrumentos, para se atingir o alvo cirúrgico. Tal deslocamento é realizado por instrumentos de superfície plana, de diferentes áreas de contacto e que exercem diferentes pressões por diferentes períodos de tempo sobre o tecido nervoso central. A pressão localizada é tanto maior quanto menor a superfície de contato entre o agente retrator e o tecido cerebral, em termos de distribuição de força por unidade de área de contacto. Paradoxalmente, pode ser interessante, tecnicamente, uma maior pressão por unidade de área 
retraindo-se uma região menos eloqüente do que uma menor pressão por unidade de área retraindo-se uma região mais eloqüente. O tempo de ação do agente retrator, assim como a força aplicada, são os principais determinantes dos mecanismos de lesão.

A lesão por retração pode ser meníngea, neural ou vascular. A lesão meníngea constitui-se da decomposição mecânica da leptomeninge que, freqüentemente, se estende ao parênquima adjacente, lacerando-o. A lesão neural macroscópica é visualizada se há ruptura da continuidade do parênquima, e a microscópica consiste no estiramento e ruptura axonais. A lesão neural secundária é conseqüência de fenômenos vasculares arteriais ou venosos. As conseqüências arteriais da retração consistem na oclusão vascular mecânica por compressão, associada ou não a tromboses imediatas ou tardias, que geram necrose de coliquação. Fenômenos semelhantes ocorrem com as veias, cuja oclusão gera tromboses retrógradas, edema e infarto hemorrágico, fato notório na trombose da veia de Labbé ${ }^{8}$. A lesão das veias em ponte, durante a retração, também é uma preocupação a ser considerada no planejamento da operação $0^{30}$. A preocupação com as repercussões da retração cerebral motivou vários estudos ${ }^{4,24,34,35}$. As técnicas utilizadas para se minimizar as consequiências de retração cerebral interferem com a força e o tempo da retração e com a ampliação ablativa do espaço de exposição. As técnicas que interferem com a força de retração atuam mediante diminuição de volume do cérebro ampliando os espaços naturais de exposição cirúrgica, ou atuam por meio da liberação das aderências aracnóideas internas do compartimento intracraniano, diminuindo a força necessária para o afastamento mecânico das estruturas. No primeiro grupo estão a drenagem liquórica, os diuréticos osmóticos e as técnicas anestésicas vasoconstritoras que diminuem o volume sangüíneo cerebral e, secundariamente, do encéfalo, e as técnicas de posicionamento dos doentes que auxiliam o deslocamento de partes do encéfalo pelo aproveitamento da força da gravidade, como por exemplo as técnicas de exposição do espaço inter-hemisférico ${ }^{15}$, ou da região pineal $^{6}$, ambas utilizando o decúbito lateral e a craniotomia no hemisfério inferiormente situado.

As técnicas de ampliação ablativa do espaço de exposição dizem respeito à remoção de tecido cerebral de áreas não eloqüentes ${ }^{13,17,23}$, ou à remoção de tecido extracerebral do viscerocrânio, que dizem respeito a todas as técnicas de abordagem à base do crânio, recentemente publicadas.

Há divergências na literatura quanto à real necessidade de amplas osteotomias. Certos autores consideram que um excesso de indicações de amplia- ções de vias de acesso pode estar ocorrendo. Numa situação cotidiana, Al Mefty e cols. ${ }^{2}$, em 1988, sobre a execução da petrosectomia, consideraram que esta diminui a retração cerebral, encurta a distância de acesso ao alvo cirúrgico, retifica o eixo longitudinal da via de acesso, oferece múltiplos eixos para o campo visual e a manipulação do instrumental e facilita a dissecção cirúrgica e a preservação das estruturas neurovasculares. Entretanto, opiniões mais conservadoras não consideram importantes osteotomias adicionais além da craniotomia frontotemporal para o tratamento cirúrgico de meningeomas esfenoidais e do tubérculo da sela, ou além da craniectomia retromastóidea para o tratamento de meningeomas petrosos e clivais.

\section{Plano de estudos}

\section{Material para estudo ou amostragem}

Podem ser usados crânios catalogados de seres humanos adultos, medidos em ambos os lados, ou seja, à direta e à esquerda, o que possibilita, ao final, o estudo de hemicrânios. As peças podem ser escolhidas aleatoriamente em relação a qualquer outra variável, exceto a idade. Quanto ao biotipo, normocéfalos, braquicéfalos e dolicocéfalos, podem ser usados sem restrição. Os crânios abertos circunferencialmente permitem a visualização das superfícies neural e visceral da lâmina óssea irregular que constitui a base do crânio.

\section{Material para mensuração}

Para a obtenção das medidas das distâncias citadas nos itens sobre a metodologia do estudo, podem ser utilizados compassos de pontas secas, réguas flexíveis, esquadros, uma fita métrica e um paquímetro. As distâncias são calculadas em milímetros. As distâncias obtidas com os compassos de pontas secas são avaliadas pelo paquímetro ou por réguas. Os ângulos, expressos em graus, são determinados a partir da aplicação de regras de geometria analítica e trigonometria às retas medidas, baseados na publicação de Vygodsky32 em 1984.

\section{Metodologia dos estudos}

Todas as distâncias medidas são consideradas linhas retas que unem dois pontos do crânio. Esses 
pontos são denominados de pontos de reparo anatômico e classificados em superficiais e profundos.

A seguir, apresentamos as definições dos pontos de reparo e dos procedimentos utilizados para a avaliação do encurtamento das distâncias de acesso cirúrgico e para a avaliação dos ângulos de exposição adicional obtidos. Seguem-se os procedimentos de escolha dos pontos de reparo superficiais e profundos e os procedimentos de mensuração. Estes podem ser estabelecidos em compartimentos se se deseja estudar, por partes ou setores, as extensões das craniotomias.

\section{Definição de pontos de reparo}

Definimos como pontos de reparo anatômico aqueles pontos onde se iniciam e terminam as distâncias lineares ou retas medidas. Os pontos não são escolhidos aleatoriamente, mas, sim, de acordo com sua relação de proximidade com estruturas profundas que costumeiramente sejam importantes parâmetros topográficos cirúrgicos, ou ofereçam dificuldade de manipulação cirúrgica, ou de acordo com sua relação de proximidade com estruturas relacionadas à craniotomia ou à superfície do campo cirúrgico. Nota-se que, previamente, os forames e saliências ósseas profundas foram usados como pontos de reparo profundos em várias publicações ${ }^{19,31}$.

Os pontos de reparo podem corresponder a estruturas anatômicas definidas como o processo clinóide anterior ou a eminência arqueada, ou podem corresponder a pontos imaginários situados a distâncias variáveis, mas proporcionais, dos pontos de reparo anatômico definidos. Nesta última situação, cita-se, como exemplo, um ponto situado na metade da distância entre o forame cego e o processo zigomático do osso frontal, ao nível da superfície interna da base do crânio, que pode servir para cálculos angulares (Figura 10).

\section{Definição de pontos de reparo superficiais}

Definimos como pontos de reparo superficiais aqueles pontos referenciais para a mensuração que delimitam a craniotomia realizada e, portanto, delimitam a superfície externa do campo cirúrgico. Por meio desses pontos, relacionados à craniotomia convencional e à craniotomia em estudo, medem-se as modificações das dimensões obtidas no campo cirúrgico. Eventualmente, um mesmo ponto de reparo pode ser utilizado nas mensurações de compartimentos diferentes de uma mesma craniotomia.

Subdividimos os pontos de reparo superficiais em externos e internos. Os pontos de reparo superficiais

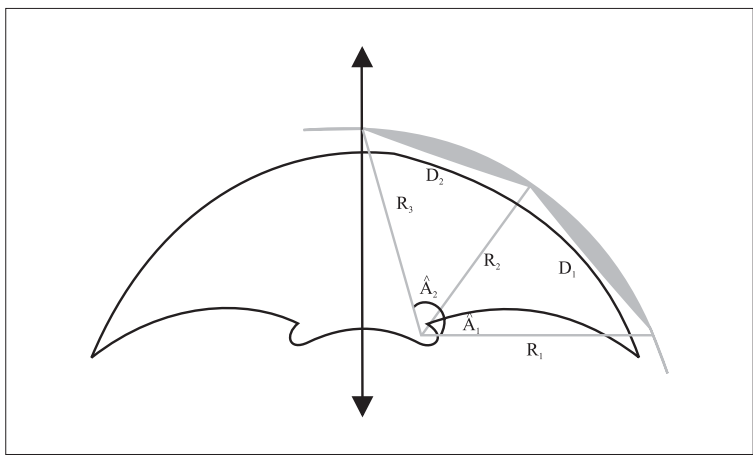

Figura 10 - Ampliação medial da craniotomia no plano semi-axial. $\hat{A}_{1}$ e $\hat{A}_{2}$ são os ângulos calculados; $R_{1}, R_{2}$ e $R_{3}$ correspondem às mesmas medidas dos planos homônimos referentes ao encurtamento das distâncias, respectivamente lateral, intermediária e mediana; $D_{1}$ e $D_{2}$ são medidas das bases dos triângulos que servirã̃o para o cálculo dos ângulos $\hat{A}_{1} e \hat{A}_{2}$.

externos dizem respeito, em geral, aos limites da craniotomia convencional, e os pontos de reparo superficiais internos dizem respeito aos limites da técnica de abordagem que estudamos, ou seja, após a remoção óssea adicional. Para complementação, subdividimos os pontos de reparo susperficiais externos em superiores (craniais) e inferiores (caudais), sendo os pontos inferiores relacionados, geralmente, à craniotomia em estudo estendida para a base do crânio, e os superiores à técnica convencional; e também em mediais e laterais, sendo os mediais costumeiramente correspondentes à técnica convencional, e os laterais às referências após a realização da craniotomia em estudo, após a remoção óssea lateral adicional.

\section{Definição de pontos de reparo profundos}

Define-se como ponto de reparo profundo uma estrutura óssea definida e pequena, que possa corresponder ao ápice de um campo cônico, e tenha relações anatômicas com estruturas viscerais ou neurais profundas e de difícil manipulação cirúrgica. Geralmente, são situadas mais próximas ao centro do osso esfenóide ou à superfície da pirâmide petrosa, pelas suas relações anatômicas e proximidade do centro do crânio.

Os pontos de reparo profundos são normalmente atingíveis por técnicas de abordagem convencionais. Entretanto, sua arquitetura vicinal dificulta o trabalho microcirúrgico seguro. Entendemos que a aplicação dos conceitos e objetivos de cirurgia da base do crânio visa melhorar, de todas as formas possíveis, a manipulação microcirúrgica das estruturas adjacentes a esses pontos de reparo escolhidos, cuja escolha será justificada à frente (Figura 11). 


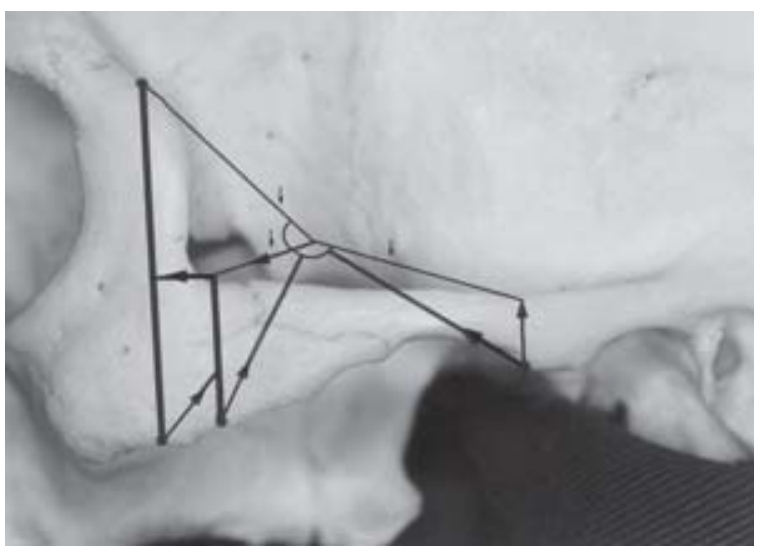

Figura 11 - Exemplo de um planejamento de estudo envolvendo a retirada do osso zigomático para se atingir um alvo profundo (ângulos e encurtamentos de distância medidos pelo estabelecimento de pontos de reparo superficiais - externos e internos - e profundos).

\section{Definição dos planos de construção do corpo humano}

Segundo Sousa ${ }^{29}$, o corpo humano é constituído pela reunião de unidades morfológicas de natureza diferente, que se separam por eixos e planos ideais. Considera-se, como eixo principal, o eixo longitudinal que une pólos não equivalentes do corpo, sendo, portanto, um eixo heteropolar ou inequipolar. Perpendicularmente a este eixo, pode-se traçar um eixo anteroposterior, ou sagital, e um transverso; o primeiro, também heteropolar e, o segundo, homopolar ou equipolar.

O deslocamento craniocaudal do eixo sagital ao longo do eixo longitudinal traça um plano sagital, que divide o corpo em dois antímeros. O deslocamento craniocaudal do eixo transverso ao longo do eixo longitudinal traça um plano frontal ou coronário que divide o corpo em dois paquímeros. O deslocamento do eixo transversal ao longo do eixo sagital traça um plano transversal ou axial que separa o corpo em segmentos superior e inferior, sendo que os planos paralelos a este separam os metâmeros (Figura 12).

As duas metades ou antímeros separadas pelo plano sagital mediano são unidades equivalentes ou homólogas, e esta homologia é denominada de homotipia. Entretanto, os vertebrados não apresentam uma construção antimérica perfeita, existindo uma assimetria normal e variável, mais acentuada quanto maior a evolução na escala ontofilogenética. Especificamente no crânio, parece haver uma tendência ao maior desenvolvimento do lado direito. Embora ambas as metades, direita e esquerda, do crânio possam ser avaliadas separadamente, podem ser consideradas como integrantes da mesma amostra.

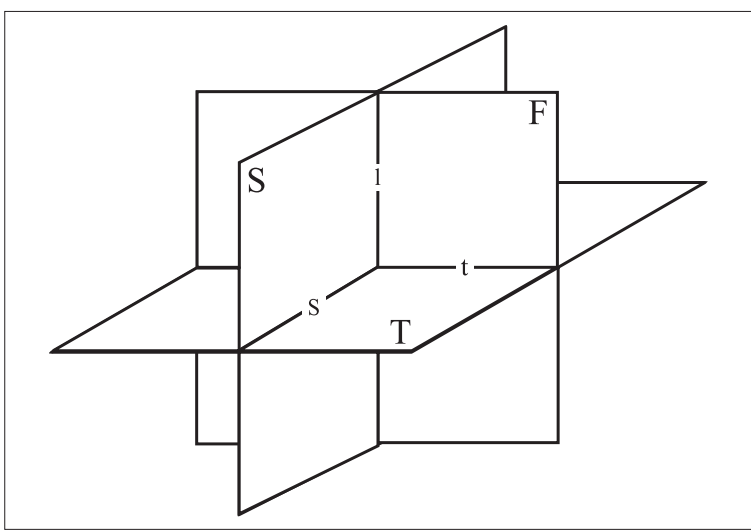

Figura 12 - Representação esquemática dos planos sagital $(S)$, frontal (ou coronário) (F), e transversal (ou axial) (T); e dos eixos sagital (s), longitudinal $(l)$ e transverso $(t)$.

Nesta análise anatômica, as medidas realizadas, lineares ou angulares, fazem parte de planos que apresentam algum paralelismo com os planos acima definidos, conforme veremos à frente. Esse paralelismo parcial pode ser identificado com o prefixo "semi".

Esse paralelismo é parcial em virtude das alterações angulares que ocorrem nos planos que são utilizados como base para as mensurações realizadas, alterações estas relacionadas aos diferentes ângulos de abordagem cirúrgica e à incongruência dos planos que constituem as fossas cranianas anterior, média, posterior e os lados da pirâmide do osso temporal. Assim, são considerados planos semi-sagitais, semicoronários ou semi-axais, de disposição radial aos eixos horizontal e vertical transverso, que passam por um ponto de reparo profundo (Figura 13). Esses planos semiparalelos

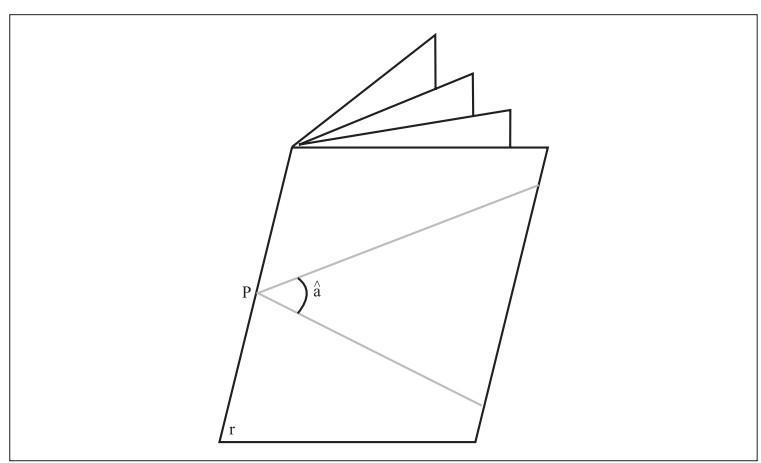

Figura 13 - Representação esquemática dos planos semisagitais e semicoronários radiais ao eixo que passa pelo ponto de reparo profundo $(P)$, e que contém o ângulo vertical correspondente $(\hat{a})$. Cada plano tem seu ângulo contido. Se a reta vertical ré colocada na posição horizontal, os planos radiais ao seu eixo serão planos semi-axiais. 
contêm retas ou distâncias dos pontos profundos aos superficiais e ângulos de ampliação do campo operatório, radialmente distribuídos.

\section{Definição do procedimento para a avaliação do encurtamento das distâncias de acesso cirúrgico}

Para se avaliar as distâncias, dos alvos cirúrgicos até a superfície do campo operatório, determinam-se os pontos de reparo profundos, individualizados para os estudos, por exemplo, das fossas cranianas anterior e média, da órbita, da fossa posterior e do ápice da pirâmide petrosa e da superfície externa da base do crânio.

São medidas as distâncias lineares adjacentes à superfície óssea da base do crânio, entre os pontos de reparo profundos e os pontos de reparo superficiais externos e internos, correspondentes à craniotomia convencional e à craniotomia em estudo. Obviamente, os pontos de reparo superficiais da craniotomia em estudo são menos superficiais (internos) do que os da craniotomia convencional (externos).

A análise comparativa das duas distâncias, que partem de um mesmo ponto de reparo profundo e atingem os pontos de reparo superficiais correspondentes às craniotomias, permite a avaliação do que definimos por "encurtamento das distâncias de acesso cirúrgico", que corresponde à quantidade absoluta e relativa ou percentual de aproximação do cirurgião ao alvo (ponto de reparo profundo). Tais distâncias podem pertencer a uma mesma reta, ou seja, terem um eixo coincidente, ou pertencer a retas diferentes, com eixos não coincidentes. A última situação, referente a eixos não coincidentes, ocorre quando a realização da craniotomia em estudo modifica a posição do plano caudal ou basal do campo cirúrgico, que corresponde à superfície caudal do cone que constitui o campo operatório. Como nos dispomos a medir o encurtamento das distâncias adjacentemente à base do crânio, a estruturação da hipótese de uma nova "base do crânio" pela nova craniotomia, em posição distinta, obrigaria a alteração do plano que conterá a segunda distância, retilínea e encurtada, a ser medida (Figuras 1, 14 e 15).

\section{Definição dos procedimentos para o cálculo dos ângulos adicionais ou de ganho de exposição cirúrgica obtidos com a craniotomia em estudo e dos planos onde se situam estes ângulos}

A mensuração, por um transferidor ou de um compasso angular, dos ângulos formados pelas

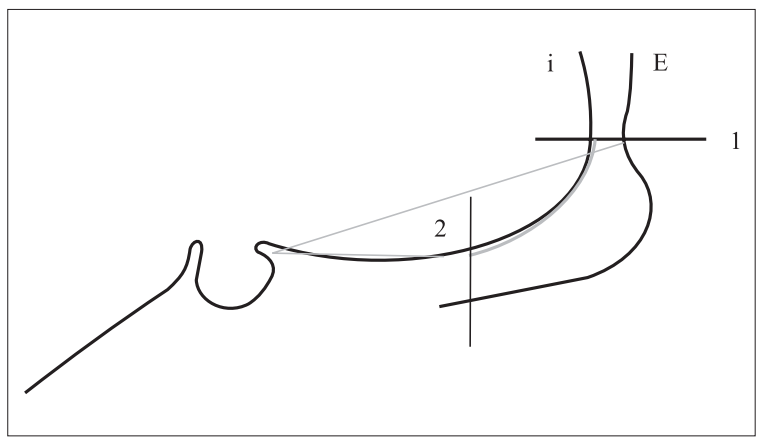

Figura 14 - Demonstração em negrito da curva ascendente da transição entre o assoalho do andar anterior e a face ascendente do osso frontal. $i=$ superfície interna; $E=$ superfície externa; 1 = ponto de projeção externa do final da curva ascendente; 2 = ponto interno do início da curva ascendente, onde interseccionam-se as retas e onde se limitam as distâncias mínimas.

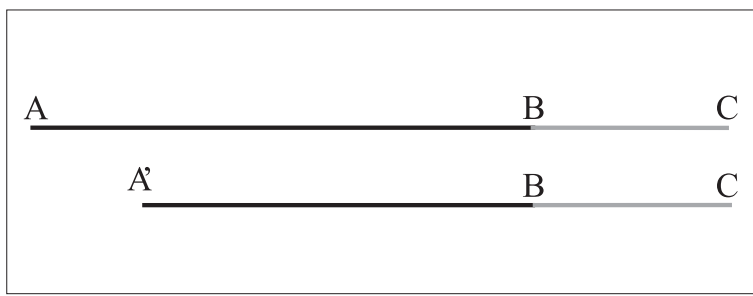

Figura 15 - Se considerarmos A como alvo profundo e A' como alvo superficial, B como o limite da craniotomia em estudo e C como o limite da craniotomia convencional, nota-se que o encurtamento BC é proporcionalmente muito mais significativo quando se considera a distância $A^{\prime} C$ em relação à distância $\mathrm{AC}$; ou $\mathrm{BC} / \mathrm{A}^{\prime} \mathrm{C}>\mathrm{BC} / \mathrm{AC}$.

estruturas ósseas da base do crânio, em relação a um ponto de reparo, não é tecnicamente possível. Para o cálculo de tais ângulos utiliza-se uma técnica que consiste em estudar triângulos cujos vértices correspondem aos pontos de reparo profundos, previamente selecionados, e cujos lados correspondem à determinação numérica das distâncias lineares entre tais pontos profundos e os pontos superficiais. Uma vez construídos os triângulos, podemos, através da trigonometria e da geometria analítica, determinar os valores de seus ângulos internos.

Os dois vértices mais próximos dos triângulos correspondem sempre a pontos de reparo superficiais, geralmente um inferior e outro superior, e o vértice mais distante, ao ponto de reparo profundo. Os dois vértices superficiais correspondem, respectivamente, a um ponto de reparo superficial externo da craniotomia convencional (superior), e a um ponto de reparo superficial externo da craniotomia em estudo (inferior). Os pontos superiores e inferiores podem 
ser substituídos por pontos mediais e laterais, quando se estuda ângulos nos planos axiais ou transversais. (Figura 10).

Os ângulos internos do triângulo podem ser calculados com fórmulas que utilizam as funções seno, cosseno e tangente. A fórmula da função cosseno não é escolhida, pois, para ângulos pequenos, de cosseno próximo a zero, a variação dos ângulos é proporcionalmente mais rápida ou proeminente do que a variação dos seus cossenos, o que prejudica o equacionamento dos cálculos. A mesma crítica pode ser efetuada para ângulos maiores, de variação proporcionalmente mais ampla do que a dos seus senos. A fórmula que utiliza a função tangente é mais adequada, pois, para valores pequenos dos ângulos, o valor da função tangente aproxima-se do valor do ângulo.

Na figura 16, a relação entre os eixos e os ângulos é exemplificada e as afirmações acima delineadas podem ser compreendidas. Informação adicional é obtida observando-se a figura 18 .

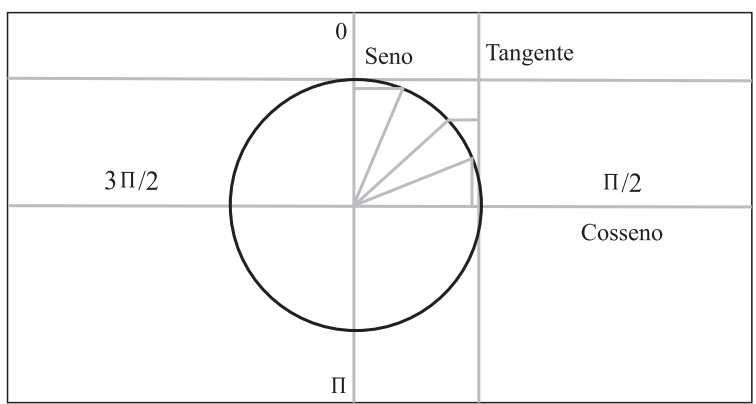

Figura 16 - Método de determinação das funções seno, cosseno e tangente dos ângulos situados no quadrante superolateral direito da figura. Notam-se os eixos das funções e a projeção dos ângulos nestes.

As funções seno, cosseno e tangente relacionamse, para cálculos de ângulos, às fórmulas específicas que consideram, no seu conteúdo, os valores do perímetro e dos lados dos triângulos. Após a obtenção dos valores dessas funções, pode-se obter o valor do ângulo através da pesquisa nas tabelas específicas, nesse caso a tabela de função tangente. Observamos que se se deseja o valor do ângulo em minutos, multiplica-se os valores decimais do ângulo por 60 . As diversas fórmulas são apresentadas na figura 18.

Os ângulos de exposição cirúrgica calculados dizem respeito aos ângulos adicionais de exposição (acrescidos) em direção ao viscerocrânio, a partir do que se supõe seriam os limites inferiores das craniotomias clássicas.

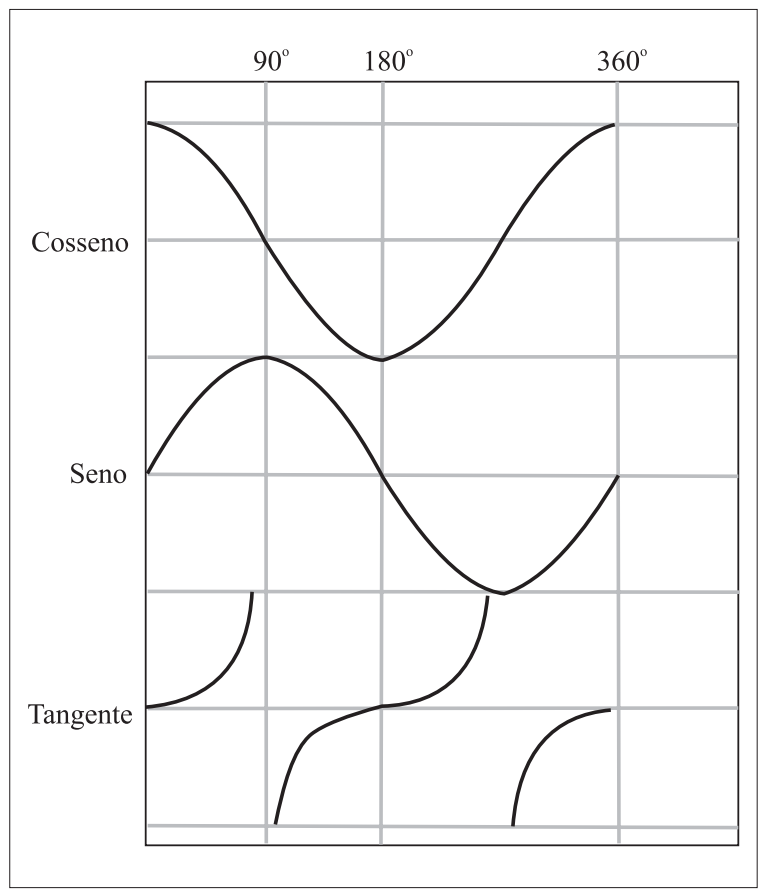

Figura 17 - Curvas de variação das funções matemáticas dos ângulos.

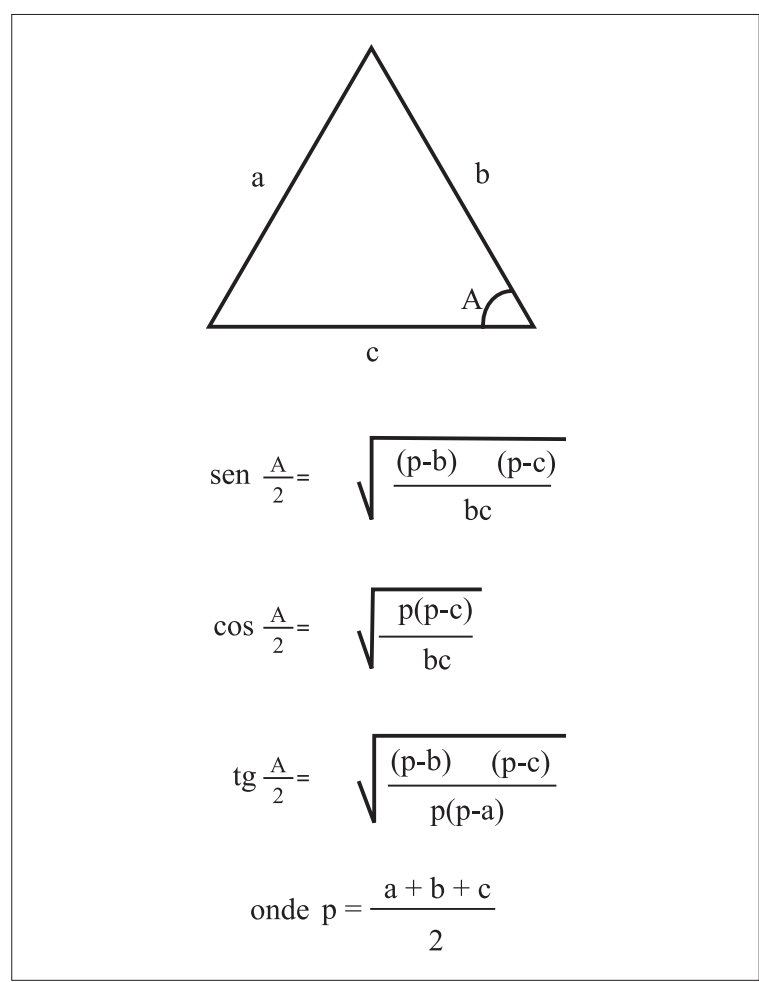

Figura 18 - Apresentação das fórmulas para o cálculo das funções matemáticas de um ângulo interno de um triângulo qualquer. $\mathbf{A}=$ ângulo a ser calculado; sen = seno; $\cos =$ cosseno; $t g=$ tangente; $\mathrm{p}=$ metade do perímetro; $\mathrm{a}, \mathrm{b}, e \mathrm{c}=$ lados do triângulo. 
Esses ângulos significam diminuição de retração cerebral por ampliação do campo operatório no sentido craniocaudal e, às vezes, lateral. Assim, o vértice dos triângulos utilizados para o cálculo dos referidos ângulos situa-se nos pontos de reparo ósseo profundos determinados para cada compartimento craniano em estudo. Esse vértice é o vértice básico, cujo ângulo interno é determinado pela fórmula das tangentes (Figuras 1 e 19).

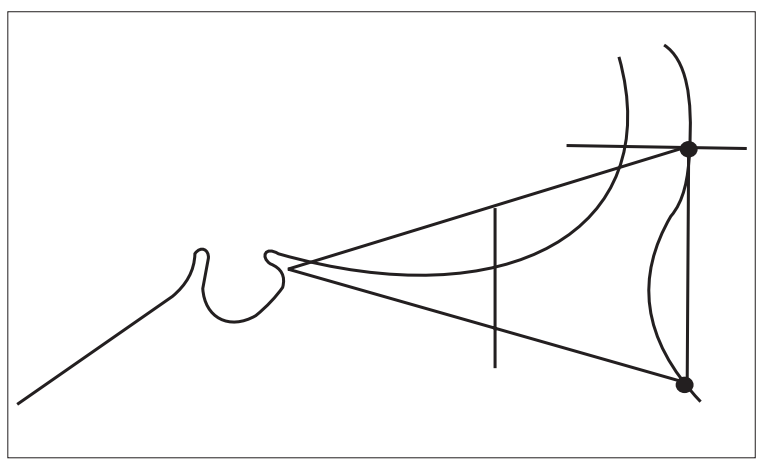

Figura 19 - Representação esquemática dos ângulos, nos planos semi-sagitais, de exposição adicional e das distâncias máxima e mínima.

A definição dos planos onde se situam os triângulos que fornecerão os valores dos ângulos adicionais de exposição é um procedimento fundamental. Os ângulos podem situar-se em planos semi-axiais, em planos semi-sagitais e em planos semicoronários, radiais ao eixo que passa por um ponto de reparo profundo. O prefixo "semi" é utilizado por não ser absoluto o paralelismo dos planos.

Os ângulos contidos nos planos semi-axiais ou transversos são ângulos de variação de exposição nos sentidos lateral e medial, à visão frontal, ou anterior e posterior, à visão lateral ou ao perfil, em relação ao ponto de reparo profundo. Esses planos são coincidentes ou semiparalelos à superfície da base do crânio. Pode-se considerar planos semi-axiais radiais em relação ao eixo horizontal de um ponto de reparo profundo, à semelhança do que descrevemos à frente em relação a planos semi-sagitais e semicoronários.

Os planos semi-sagitais radiais são definidos como planos quase paralelos ao plano sagital, de distribuição radial em relação a um eixo longitudinal vertical que passa por um ponto de reparo profundo (Figuras $13 \mathrm{e}$ 20). Esses planos conterão triângulos para o estudo de ângulos de ganho no sentido súpero-inferior ou craniocaudal.

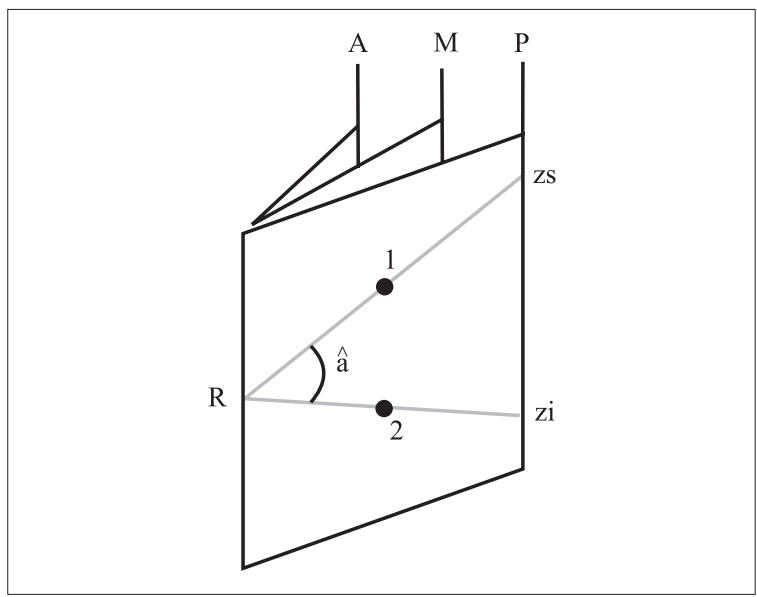

Figura 20 - Representação esquemática dos triângulos contidos nos planos semicoronários radiais ao ponto de reparo profundo $(R)$, que contém os eixos anterior $(A)$, médio $(M)$ e posterior $(P)$. Notam-se o triângulo para estudo do ângulo de ganho â, os pontos zigomáticos superior e inferior ( $\mathrm{Zs}$ e $\mathrm{Zi}$ ), e os pontos de reparo superficiais internos ( 1 e 2), que são utilizados para o cálculo do encurtamento das distâncias, quando os eixos cruzam o limite da fossa craniana média. Trata-se do estudo, nas relações zigomáticas das fossas craniana média, posterior e da base craniana externa, dos ângulos de ganho nos planos semicoronários.

Os planos semicoronários radiais são definidos como planos quase paralelos ao plano coronário, de distribuição radial em relação a um eixo longitudinal vertical que passa por um ponto de reparo profundo. Esses planos também contêm triângulos para o estudo de ângulos de ganho no sentido súpero-inferior ou craniocaudal e as mesmas figuras esquematizadas anteriormente se prestam como material explicativo se colocadas em situação perpendicular (Figuras 13 e 20).

\section{Discussão}

As craniotomias ampliadas para a base do crânio podem ser submetidas a uma análise morfométrica para avaliação de suas vantagens em relação às craniotomias convencionalmente utilizadas para a execução das vias de acesso, pelo desenvolvimento de técnicas de mensuração baseadas na trigonometria e na geometria analítica, que se revelam adequadas para o cálculo dos valores que se deseja determinar.

Tal metodologia matemática mostra-se eficaz para a avaliação de vias de acesso neurocirúrgicas em geral ${ }^{16}$ e pode ser utilizada para estudos orbitozigomáticos, assim como o de abordagens posterolaterais adjacentes 
à pirâmide petrosa do osso temporal. Nas poucas publicações prévias, onde se representam graficamente ângulos de exposição cirúrgica, a técnica usada para se calcular esses valores não é exposta pelos autores. Nota-se, na literatura em geral, uma análise intuitiva das diversas vias de acesso cirúrgico quanto aos benefícios adicionais oferecidos, baseada em interpretações pessoais durante os procedimentos, sem haver uma crítica estruturada sobre dados concretos concernentes a tais benefícios.

Nos protocolos de coleta de dados utilizados como material para o estudo estatístico descritivo, as modalidades básicas de mensuração devem incluir o estudo do encurtamento das distâncias de acesso cirúrgico, o estudo dos ângulos de ganho para ampliação basal da craniotomia nos planos semisagitais e semicoronários em relação a um ponto de reparo profundo, e o estudo dos ângulos de ganho nos planos semi-axiais em relação a um ponto de reparo profundo, que correspondem a expansões transversais do campo operatório.

O estudo do encurtamento das distâncias de acesso cirúrgico é realizado pela comparação entre dois valores, um obtido pela realização da craniotomia convencional e o outro obtido mediante realização da craniotomia em estudo. São calculadas as diferenças entre essas distâncias, que vão de um ponto de reparo superficial a um profundo, em eixos quase coincidentes, em valores absolutos (milímetros) e relativos (percentuais). Uma prova de comparação entre médias pode ser instituída.

O estudo dos ângulos de ganho de exposição basal da craniotomia nos planos semi-sagitais e semicoronários não é comparativo, pois considera-se que a craniotomia rotineira ofereceria um ângulo nulo, ou, hipoteticamente tangente à base do crânio. Assim, medem-se os ângulos adicionais de exposição obtidos pela craniotomia em avaliação, que desloca inferiormente a superfície basal do campo operatório. Os ângulos de ganho nos planos semi-axiais são calculados em termos de ganho de exposição lateral, entretanto duas circunstâncias especiais são consideradas.

Uma falha metodológica ocorre quando o valor de um dos lados do triângulo hipotético, adjacente ao ângulo em estudo, apresenta valor numérico maior ou igual ao semiperímetro, impossibilitando a construção daquela figura geométrica e tornando o número, cuja raiz quadrada deveria ser extraída, negativo ou igual a zero, o que anula o cálculo da metade da tangente, segundo a fórmula apresentada na figura 18. Não são realizadas novas mensurações, pois tal correção seletiva implicaria em se ocultar essa falha metodológica pela perda da casualidade dos métodos de mensuração, visto que, previamente à aceitação dos valores definitivos das medidas, a repetição da técnica de mensuração já automatiza o procedimento. Aceita-se os valores obtidos levando-se em consideração essa hipótese comprovada de falha do método analítico que, entretanto, como fenômeno matemático isolado, não desqualifica os outros ângulos obtidos. Essa ocorrência é notada mais freqüentemente nos cálculos de ângulos de pequeno valor, e muito raramente nos cálculos de ângulos de maior valor.

Essa observação sugere que a metodologia de obtenção de medidas apresenta deficiências no que concerne ao cálculo de ângulos extremamente agudos, cujo lado oposto do triângulo será muito pequeno e cujos lados adjacentes, muito longos, apresentam maior dificuldade de mensuração. Assim, a diferença entre os dois lados adjacentes longos poderá ser maior ou igual ao lado oposto, impossibilitando a construção do triângulo.

Nota-se que quanto mais superficial o ponto de reparo profundo maior será a ampliação do ângulo de exposição. Tal situação pode ser exemplificada na figura 21 e é válida também para alvos cirúrgicos compostos de regiões lineares e não puntiformes.

Da mesma forma, quanto mais superficial for o ponto de reparo profundo ou alvo cirúrgico, maior será a proporção do encurtamento da distância de acesso a ele após a realização da craniotomia em estudo, conforme demonstra a figura 15.

Como os pontos de reparo, geralmente, são escolhidos na profundidade, e nessa topografia obtém-se

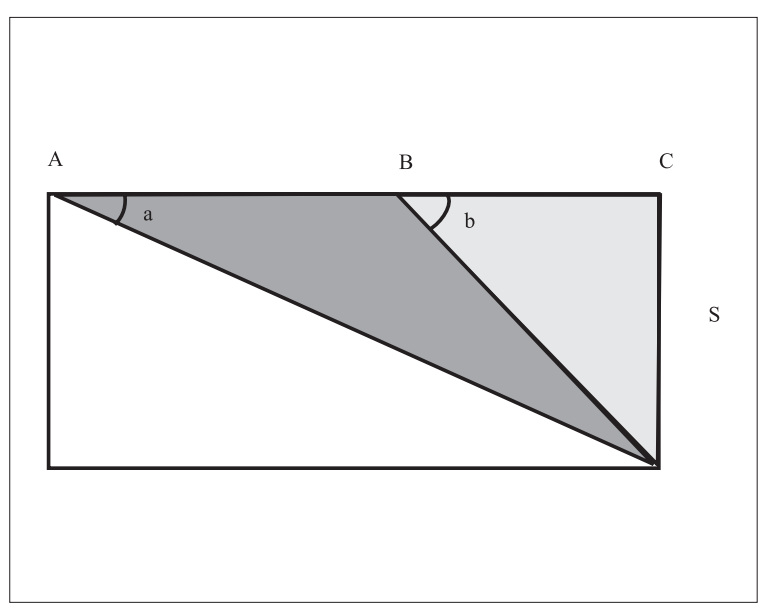

Figura 21 - Esquema representativo da ampliação do ângulo de exposição quando se consideram os pontos de reparo profundos $A$ e $B$, o primeiro mais distante da superficie. Nota-se que $a<b . S=$ superfície de ampliação basal da craniotomia. Em relação a alvos cirúrgicos mais superficiais, o aumento da exposição angular é maior. 
sempre o mínimo ganho em relação à proporção do encurtamento da distância e ao ângulo de exposição basal adicional, se considerarmos a comparação com pontos de reparo menos profundos os benefícios da técnica são sempre maiores. Se todos os pontos de reparo profundos estão adjacentes à região central do crânio e se comprova ganhos, certamente os ganhos serão ainda maiores para pontos de reparo profundos mais próximos à superfície.

Se considerarmos o crânio como uma esfera, a análise bidimensional aqui realizada pode ser promovida para um nível tridimensional, conforme revela a figura 22.

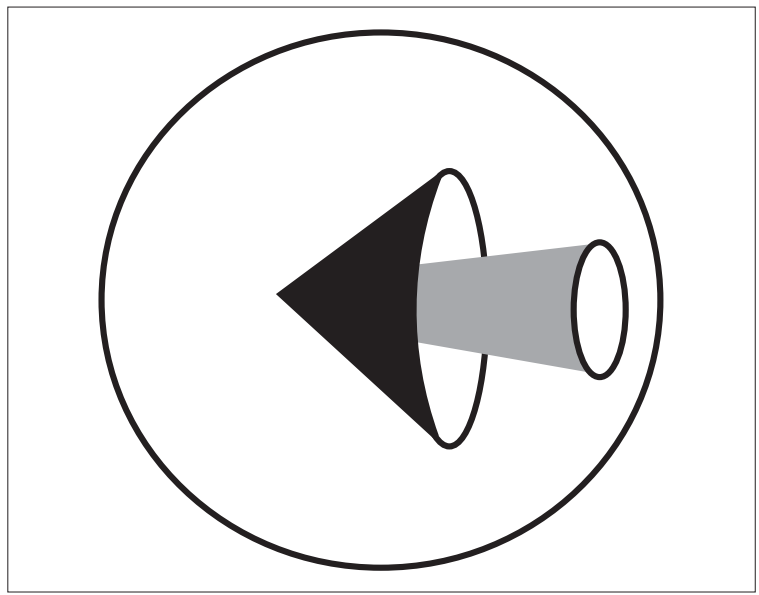

Figura 22 - Perspectiva tridimensional da avaliação dos campos operatórios, considerados como cônicos. Neste trabalho realizou-se um estudo bidimensional por meio de triângulos obtidos pela secção longitudinal dos cones, que pode ser intuitivamente correlacionado ao estudo tridimensional.

O estudo baseado eminentemente em remoções ósseas é justificado por apresentar o esqueleto, como continente e sustentáculo dos tecidos moles, a função de fixação estática ou dinâmica. A partir da remoção do esqueleto craniano, as estruturas não ósseas do viscerocrânio podem ser deslocadas, manipuladas, incisadas e excisadas, com ou sem reconstrução posterior, na dependência do radicalismo do procedimento, este determinado pelos objetivos do cirurgião e pelas características da doença neoplásica. Levandose em conta a possibilidade de manipulação associada do músculo temporal com o arco zigomático, as vantagens angulares são nítidas, conforme foi demonstrado por Pitelli ${ }^{21}$ em 1984.

O estudo das osteotomias pode ser organizado de maneira compartimentada, para que as decisões cirúrgicas possam ser tomadas a partir de dados específicos em relação ao compartimento por onde se vai trabalhar. Assim, uma análise setorial torna-se válida inclusive para técnicas de abordagem mais restritas.

Por exemplo, a remoção do bloco orbitoesfenozigomático implica a desestruturação da órbita e da região infraorbitária, permitindo o deslocamento do conteúdo orbitário e a intrusão cirúrgica através dos ossos malar e maxilar. Tal retalho ósseo é recolocado e permite a manutenção estética e funcional. Obviamente, numa situação de osteomielite pós-operatória, a remoção deste fragmento causaria conseqüências maiores e de mais difícil correção.

As osteotomias podem ampliar significativamente o campo cirúrgico em direção caudal, permitir o acesso combinado ao esplancnocrânio e aproximar as regiões esfenoidal e clival, externas e internas, da superfície operatória. Às vezes, a facilitação obtida por essas técnicas de abordagem pode dar-se isoladamente às custas do encurtamento das distâncias de acesso. Em relação à cisterna interpeduncular e à região supra-selar, notou-se que o acesso pré-temporal ou temporopolar convencional poderia ser ampliado com a remoção do arco zigomático quando se desejava uma ampliação de visão na parte cranial da fossa média. A remoção orbitoesfenozigomática estenderia a área visualizada ao hipotálamo e à região supra-selar com maior liberdade ${ }^{10}$.

Em relação à fossa craniana anterior, onde várias osteotomias orbitárias foram propostas para facilitar as técnicas de abordagem subfrontal, a remoção do rebordo orbitário superior, sem se considerar a retirada completa do teto da órbita, aproxima o cirurgião do processo clinóide anterior cerca de $2 \mathrm{~cm}$, reduzindo em aproximadamente 30\% a distância convencional, principalmente nos extremos da craniotomia. Tal remoção também amplia caudalmente o campo operatório em quase $2 \mathrm{~cm}$, ou aproximadamente $20^{\circ}$, principalmente no setor lateral, em relação a alvos profundos. As vantagens são otimizadas ao se considerar alvos mais superficiais como o jugo esfenoidal, a cisterna da lâmina terminal, a órbita e a lâmina crivosa do osso etmóide ${ }^{3,16,27}$. Calcula-se que a retração subfrontal isolada oferece um ângulo de acesso de $11^{\circ}$, que se expande para $19^{\circ}$, ou $75 \%$, com a remoção do rebordo orbitário superior e que a remoção do rebordo medial das órbitas amplia o ângulo de exposição da via de acesso transbasal ${ }^{3,16,18,27}$.

A ampliação do segmento frontal da craniotomia medialmente, até a linha média, aumenta o ângulo de exposição do processo clinóide anterior no plano transversal em aproximadamente $30^{\circ}$, aumentando em 
mais de 50\% o ângulo respectivo convencional. Torna-se interessante preconizar tal extensão frontal da técnica de abordagem para a manipulação cirúrgica da região selar ${ }^{16}$.

Em relação à órbita, a remoção de suas margens superior e lateral encurta radialmente a distância de acesso cirúrgico até o seu ápice em quase $2 \mathrm{~cm}$, ou em cerca de um a dois terços e múltiplas osteotomias adicionais são possíveis.

A remoção do rebordo lateral da órbita e do osso malar oferece aproximadamente $20^{\circ}$ adicionais de exposição lateral no acesso anterior à intersecção das fissuras orbitárias. Tal remoção também oferece um ângulo de acesso no plano semi-sagital ao ápice da órbita de aproximadamente $60^{\circ}$ configurando uma área de manipulação cirúrgica livre de sustentação óssea de aproximadamente $10 \mathrm{~cm}^{2}$. Assim, há a possibilidade de se abordar a região posterior da órbita inferiormente ou, se se deseja trabalhar pela sua face lateral, a possibilidade de se abordar o centro, o teto e a região infraorbitária em conjunto, com boa perspectiva de reconstrução ${ }^{16}$.

Em relação à fossa craniana média, a remoção do bloco orbitoesfenozigomático, que permite o acesso anterolateral ao corpo do osso esfenóide e adjacências, encurta as distâncias de acesso cirúrgico em torno de $4 \mathrm{~cm}$ ou de dois a quase três quartos, além de fornecer rotas de tráfego cirúrgico antes não disponíveis. Fornece também uma exposição adicional no setor lateral do campo de trabalho frontal em torno de $20^{\circ}$, e uma exposição basal, nesse mesmo campo, de aproximadamente $7 \mathrm{~cm}$ ou $50^{\circ}$. Calcula-se que a remoção do rebordo orbitário lateral amplia em $10^{\circ}$ o campo cirúrgico, medialmente, em direção ao polo e face medial do lobo temporal, no plano transversal ou axial ${ }^{3,27}$.

Retirando-se o osso malar, a órbita e as asas do osso esfenóide podemos atingir anteriormente o setor polar da fossa craniana média e a parte anterior da fossa infratemporal associando-se a via transmaxilar. A região pterigóidea pode ser parcialmente exposta e lesões temporais combinadas podem ser operadas. A remoção do arco zigomático aproxima o compartimento medial da fossa craniana média da superfície em torno de $3 \mathrm{~cm}$, reduzindo pela metade a distância de acesso às regiões selar, do seio cavernoso e do gânglio trigeminal. Pontos menos profundos, como o forame espinhoso, têm seu acesso ainda mais beneficiado ${ }^{16}$.

A remoção do arco zigomático, considerado exclusivamente como estrutura óssea, amplia caudalmente o ângulo de acesso à região para-selar principalmente no trabalho mais anterior, onde tal arco é mais largo e se produz uma ampliação de aproximadamente $40^{\circ}$. No segmento posterior, onde o arco é delgado, a ampliação angular caudal é pequena, em torno do mínimo de $4^{\circ}$ para o ponto de reparo profundo menos beneficiado, o que torna o encurtamento da distância um benefício mais importante do que a ampliação angular nesta região. Entretanto, a liberação dessa estrutura permite a liberação do músculo temporal e do processo coronóide da mandíbula, cujos deslocamentos propiciam, na realidade, ampliação angular caudal significativa nas técnicas de abordagem da região subtemporal e da fossa infratemporal. Considera-se a ampliação de exposição significativa e aumentada de $8^{\circ}$ só com a retração subtemporal para $14^{\circ}$ com a remoção zigomática, ou $86 \%$; outros acreditam que a retração cerebral sem zigomaticotomia oferece um ângulo de abordagem de $20^{\circ}$ para a cisterna interpeduncular ${ }^{3,22,25,27}$.

A remoção do teto do meato auditivo externo permite uma ampliação inferior do campo operatório de $17^{\circ}$ para $27^{\circ 28}$.

Pitelli ${ }^{21}$, em 1984, demonstrou que, removendo o arco zigomático e retraindo inferiomente o músculo temporal, o ângulo de exposição caudal aumenta, para a exposição da fossa média, em valores de até pouco mais de $20^{\circ}$, da borda do tentório, e da bifurcação da artéria basilar. A técnica de mensuração utilizada por aquele autor foi a alteração do eixo do campo visual do microscópio cirúrgico antes e depois da ampliação zigomática da craniotomia.

$\mathrm{O}$ radicalismo das ressecções deve equilibrar os conceitos de ressecabilidade e preservação funcional. A ampliação das técnicas de abordagem pode permitir, hipoteticamente, uma melhora das condições da ressecção da neoplasia preservando-se a função. Entretanto, sob o ponto de vista oncológico, em grande parte das neoplasias ainda não foi definido o papel da proporção da ressecção na sobrevida dos pacientes, principalmente em se considerando o avanço da terapêutica adjuvante e a velocidade de recorrência dos diferentes tumores.

A diminuição da retração do cérebro, à custa da expansão do campo operatório em direção ao viscerocrânio, minimiza as seqüelas pós-operatórias pelo alívio da pressão da espátula sobre o tecido nervoso e vasos corticais e pela preservação do sistema venoso tributário sinusal. É interessante considerar que a retração gera isquemia e prejuízo do mecanismo de autorregulação, e déficits ocorrem em animais de laboratório quando a pressão de retração excede 20 torr, o mesmo valor de pressão intracraniana quando aparecem ondas patológicas no traçado de monitorização ${ }^{4}$. Adicionalmente, a pressão de perfusão cerebral nas áreas sob pressão de retração é menor do que no encéfalo livre, e uma hipotensão arterial causará isquemia adicional naquelas áreas, tanto mais intensa 
quanto maior a pressão de retração. Notou-se que, na cirurgia dos tumores, a retração é maior no início do procedimento do que na fase de exérese e, na cirurgia dos aneurismas, o inverso ocorre ${ }^{35}$.

Deve-se considerar, nessa fase, a teoria da inversão dos cones que constituem os campos cirúrgicos. Assim, ao se trabalhar através do viscerocrânio para atingir a base do crânio a ampla remoção óssea permite a otimização dos princípios oncológicos do procedimento. Tal raciocínio não é válido para a cirurgia intracerebral, visto que, nessa situação, se procura trabalhar através de uma pequena corticotomia ou corticectomia para se atingir massas às vezes grandes. Desse modo, o raciocínio do campo cônico está invertido, trabalhando o cirurgião pelo ápice do cone, no córtex, em direção ao tumor, relacionado à base daquela figura geométrica. Essa teoria da inversão do cone é a base da neuroendoscopia transcerebral.

\section{Conclusão}

A análise matemática é útil para se estudar o campo operatório, o acesso multidirecional, e a distância desde a superfície do campo cirúrgico até o alvo do cirurgião, e os ângulos de exposição adicional obtidos. A possibilidade de minimizar-se a retração do tecido encefálico é, assim, uma realidade demonstrável e a possibilidade de reconstrução osteoplástica mantém a arquitetura craniofacial, pois recupera as distâncias encurtadas e as ampliações angulares de exposição cirúrgica.

\section{Referências}

1. ADEGBITE AB, KHAN MI, PAINE KWE, TAN,LK: The recurrence of intracranial meningiomas after surgical treatment. J Neurosurg 58:51-6, 1983.

2. AL MEFTY O, FOX JL, SMITH RR: Petrosal approach for petroclival meningiomas. Neurosurgery 22:510-7, 1988.

3. ALAYWAN M, SINDOU M: Fronto-temporal approach with orbito-zygomatic removal. Surgical anatomy. Acta Neurochir (Wien) 104:79-83, 1990.

4. ALBIN MS, BUNEGIN L, DUJOUNY M, BENNES MH, JANETTA PJ, WISOTZKEY HW: Brain retractor pressure during intracranial procedures. Surg Forum 26:499-500, 1975.

5. ARNOLD H: Problems in the treatment of basal meningiomas. Acta Neurochir (Wien) 31:281 1975.

6. AUSMAN JI, MALIK GM, DUJOVNY M, MANN R: Threequarter prone approach to the pineal-tentorial region. Surg Neurol 29:298-306, 1988.

7. BARBARO NM: GUTIN PH, WILSON CB, SHELINE GE, BOLDREY EB, WARA WM: Radiation therapy in the treatment of partially resected meningiomas. Neurosurgery 20:525-8, 1987.
8. CAMBRIA S: Thrombosis of the cerebral vein of Labbé with hemorrhagic cerebral infarction. Rev Neurol (Paris) 136:321-6, 1980.

9. CARELLA RJ, RANSOHOFF J, NEWALL J: Role of radiation therapy in the management of meningioma. Neurosurgery 10:332-9, 1982.

10. DAY JD, GIANOTTA SL, FUKUSHIMA T: Extradural temporopolar approach to lesions of the upper basilar artery and infrachiasmatic region. J Neurosurg 81:2305, 1994.

11. DORON Y, BOROVICH B: Recurrence of meningiomas. In SAMII M (ed): Skull Base Surgery. Basel, Karger, 1994, pp 210-2.

12. DUMA CM, LUNSFORD LD, KONDZIOLKA D, HARSH GR, FLICKINGER JC: Stereotactic radiosurgery of cavernous sinus meningiomas as an addition or alternative to microsurgery. Neurosurgery 32:699-705, 1993

13. HEROS RC: Brain resection for exposure of deep extracerebral and paraventricular lesions. Surg Neurol 34:188-95, 1990.

14. JOAQUIM MAS, ALMEIDA GGM, PITELLI SD, VELLUTINI E: Abordagens orbito-zigomática e frontotemporo-orbito-zigomática. Arq Bras Neurocir 6:157-64, 1987.

15. JOAQUIM MAS, HONDA PN, VELASCO OP, TEIXEIRA MJ CESCATO WS, MANREZA LA: Empiema interhemisférico unilateral. Considerações técnicas. Arq Bras Neurocir 7:47-52, 1988

16. JOAQUIM MAS: Análise craniométrica das extensões orbitária, esfenoidal e zigomátrica da craniotomia frontotemporal: contribuição ao estudo das técnicas de abordagem cirúrgica à região anterolateral da base do crânio. Tese (Doutorado). Faculdade de Medicina da Universidade de São Paulo, São Paulo, 1996.

17. KEMPE LG, VANDERARK GD: Anterior communicating artery aneurysms. Gyrus rectus approach. Neurochirurgia (Stuttgart) 14:63-70, 1971.

18. LESOIN F, PELLERIN P, DHELLEMMES P, JOMIN M: Usefulness of the orbitofrontomalar approach associated with bone reconstruction for frontotemporosphenoid meningiomas. In DOLENC VV (ed) The Cavernous Sinus. Wien, Springer-Verlag, 1987, pp 332-40.

19. OLIVEIRA E, RHOTON Jr AL, PEACE D: Microsurgical anatomy of the region of the foramen magnum. Surg Neurol 24:293-352, 1985

20. PETTY AM, KUN LE, MEYER GA: Radiation therapy for incompletely resected meningiomas. J Neurosurg 62:502-7,1985.

21. PITELLI SD: Modificação da craniotomia subtemporal. Contribuição ao acesso cirúrgico á bifurcação da artéria basilar. São Paulo, 1984. 118p. Dissertação (Mestrado) - Faculdade de Medicina, Universidade de São Paulo.

22. PITELLI SD, ALMEIDA GGM, NAKAGAWA E, MARCHESE AJT, CABRAL ND: Basilar aneurysm surgery: The subtemporal approach with section of the zygomatic arch. Neurosurgery 18:125-8, 1986.

23. POOL LJ: Timing and techniques in the intracranial surgery of ruptured intracranial aneurysms of the anterior communicating artery. J Neurosurg 19:378-88, 1962.

24. ROSENORN J, DIEMER NH: Reduction of regional cerebral blood flow during brain retraction pressure in the rat. J Neurosurg 56:826-9, 1982.

25. SHIOKAWA Y, SAITO I, AOKI N, MIZUTANI H: Zygomatic temporopolar approach for basilar artery aneurysms. Neurosurgery 25:793-7, 1989.

26. SIMPSON D: The recurrence of intracranial meningiomas after surgical treatment. J Neurol Neurosurg Psychiatry 20:22-39, 1957. 
27. SINDOU M, ALAYWAN M: La dépose orbitaire et/ou zygomatique dans l'abord des lesions proches de la base du crâne. Technique chirurgicale, étude anatomique et analyse d'une serie de 24 cas. Neurochirurgie 36:22533, 1990.

28. SINDOU M, FOBE JL: Removal of the roof of the external auditory meatus in approaching the tentorial notch through a low temporal craniotomy. J Neurosurg 74:520-2, 1991.

29. SOUSA OM: Anatomia topográfica. 3. ed. São Paulo, Rossolillo, pp 41-6, 1970.

30. SUGITA K, KOBAYASHI S, YOKOO A: Preservation of large bridging veins during brain retraction. J. Neurosurg 57:856-8, 1982.

31. TEDESCHI H, RHOTON AL: Lateral approaches to the petroclival region. Surg Neurol 41:180-216, 1994.

32. VYGODSKY M: Mathematical handbook. Elementary mathematics. Moscow, Mir Publishers, 1984,. pp 3058, 319-24, 359-65.
33. YAMASHITA J, HANDA H, IWAKI K, ABE M: Recurrence of intracranial meningiomas, with especial reference to radiotherapy. Surg Neurol 14:33-40, 1980

34. YOKOH A, SUGITA K, KOBAYASHI S: Intermittent versus continuous brain retraction. An experimental study. J Neurosurg 58:918-23, 1983.

35. YOKOH A, SUGITA K, KOBAYASHI S: Clinical study of brain retraction in different approaches and diseases. Acta Neurochir (Wien) 87:134-9, 1987.

Original recebido em janeiro de 2003

Aceito para publicação em outubro de 2003

\section{Endereço para correspondência:}

Marcos Augusto Stávale Joaquim

Alameda Campinas, 1360 - $16^{\circ}$ andar

CEP 01404-002 - São Paulo, SP 